\title{
IS IT SAFE TO DESIGN A BUILDING STRUCTURE WITH SIMPLE JOINTS, WHEN THEY ARE KNOWN TO EXHIBIT A SEMI-RIGID BEHAVIOUR?
}

\author{
Marc BRAHAM ${ }^{1}$, Jean-Pierre JASPART ${ }^{2}$
}

\begin{abstract}
It is shown, by means of computer simulations of the behaviour of a real structure, that it is safe to design a building with the assumption of pinned joints, even when they show a semirigid behaviour. This result is however limited to the cases where the joints show a high ductility, i.e. a capacity of large deformation before the rupture of either the bolts or the welds. Only in few, probably unrealistic cases, this assumption will lead to unsafe results, the lack of safety being however very small, amounting only to a few per cents.
\end{abstract}

Key words: Joints, semi-rigidity, structural behaviour.

\section{INTRODUCTION}

Depending on their education, or the local or national habits, engineers do consider $a$ priori some joints as pinned, what is usually referred to as "simple joints" in actual codes. A good example is the beam-to-column joints made with a thin and non-extended end-plate, as shown on Figure 1. However, there has been no real, reliable mean, up to recently, to get convinced that such joints really behave as hinges, i.e. transmit no bending moment.

On the contrary, one should realise that all joints exhibit a certain rotational restraint to an applied loading; in other words they are likely to be classified as semi-rigid (the "Eurocode 3" wording). This of course depends on the relative stiffness they show as compared to the flexural stiffness of the beams and the columns of the framing in which they are used. Anyway, in the absence of definite information, usage and possible experience have prevailed during long.

It is only recently that extensive studies on the subject have been performed, and rules have been settled. This concluded in the edition of a European normative document, Annex J ${ }^{1}$ Chief Design Engineer, Ceng, FIStructE, ASTRON Buildings S.A., Diekirch, Luxembourg

${ }^{2}$ Associate Professor, FNRS Research Director, University of Liège, Belgium 
of Eurocode 3 [1], which allows for the evaluation of the mechanical characteristics (rotational stiffness, bending resistance, shear resistance, failure mode and ductility) of a great deal of joints. Also, the classification system of joints (simple, semi-rigid or rigid) proposed by this document, offers indications on how to proceed for the modelling of joints in the analysis of a structure.
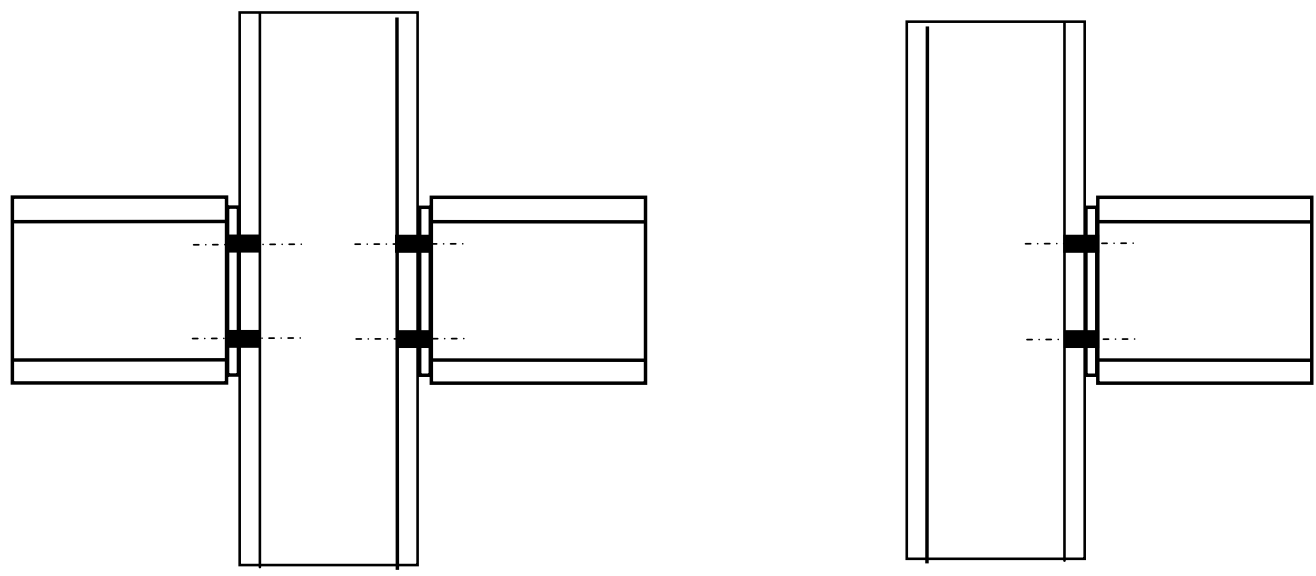

Figure 1 - Beam-to-column joint with a non-extended end plate

In the meantime, many buildings have been designed, and built, which show such joints. One could now object, at the light of Eurocode 3 and its classification system of joints, that their design is suspicious and possibly unsafe. Indeed the joints of these buildings have been considered as pinned, though they probably are, in many cases, semi-rigid, thus show a resistance in bending.

Similarly, for buildings to be designed in the future, one should know whether this assumption must definitely be eliminated, or if such a practice may be further used. One should also keep in mind that practitioners are interested by simple design methods, and the assumption of pinned joints in the cases of Figure 1 is certainly offering advantage to this respect.

In order to give an answer to these questions, several aspects must be considered:

- 1 - the deformation of the structure, in other words its behaviour at the SLS;

- 2 - the plastic resistance of the structure;

- 3 - the elastic critical resistance of the structure;

- 4 - the elasto-plastic resistance of the structure (in fact its actual resistance);

- 5 - the behaviour of the joints.

It is not the intention of the present paper to discuss all these aspects. Only items 1,2 , 4 and 5 are here after explicitly addressed.

The most recent studies on all these items have been performed in Sheffield [2] and Liège [3]. These two studies, however limited to isolated columns, are in perfect agreement and their conclusion is that the assumption of pinned joints is safe. Previously, Jaspart [4], however studying a slightly different aspect of the behaviour of joints, had already concluded in the same way for complete structures, sway structures as well as non-sway structures.

The paper illustrates, through computer numerical simulations of a precise example referring to an existing building, that the conclusions of the above-mentioned reports are correct. The behaviour of the joints of this structure, in terms of characteristic momentrotation curves (so-called M- $\phi$ curves) has been evaluated by means of Eurocode 3 Annex J. However, one of the actual joints had previously been submitted to testing [8]. Therefore a 
"Eurocode 3 model - test" comparison has thus been made in order to evaluate the level of accuracy of the Eurocode 3 calculation for the other joints, which are similar but not identical.

\section{DEFINITION OF THE STRUCTURE}

\subsection{The geometry, the material and the loading}

The frame is shown in Figure 2. It is a braced structure. The profiles for the columns and beams are described in Table 1 . It can be seen that two types of steel are used, as was the case in the real building. As the structure is braced, no wind load has been considered. The joints of beams B1 to the central column have been submitted to test and their behaviour is reported in [8]. The other joints are discussed under 2.2 below.

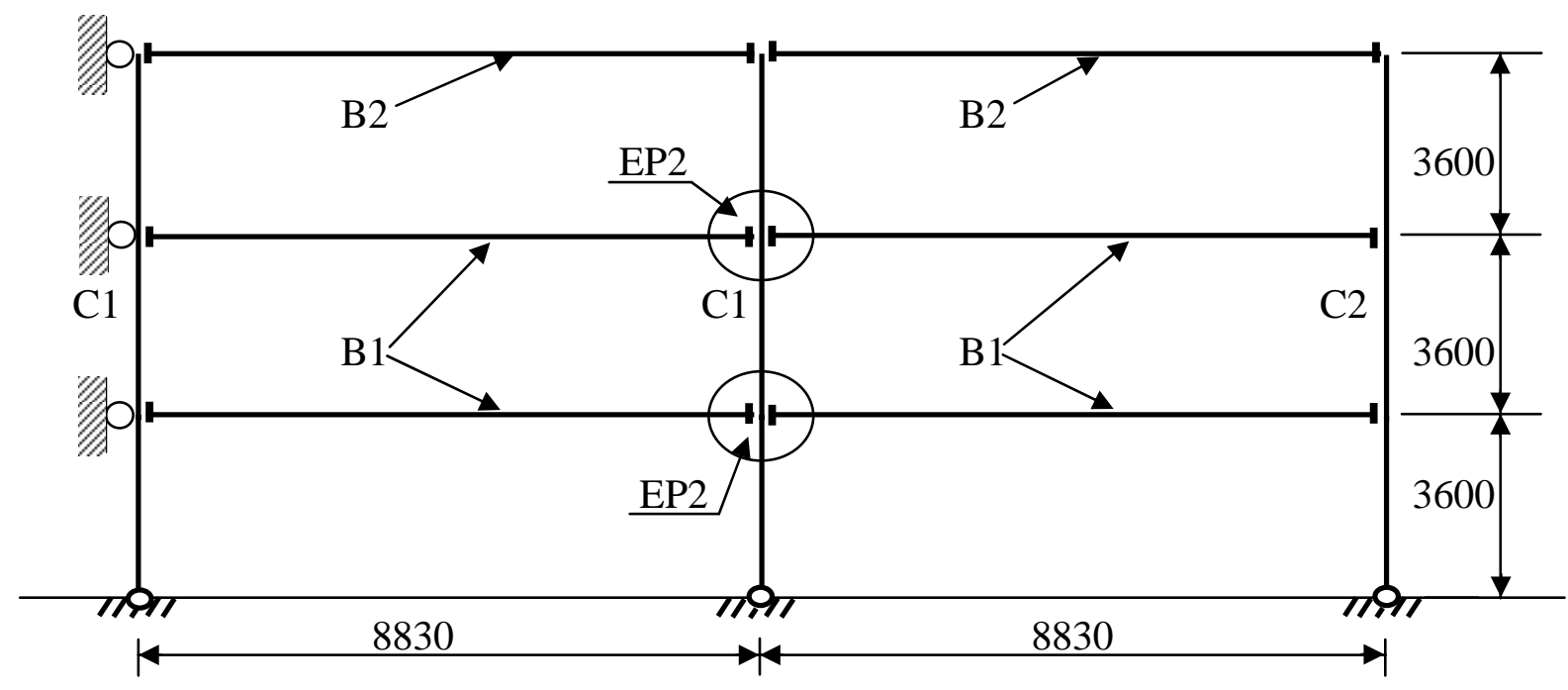

Figure 2 - Description of the structure

\begin{tabular}{|c|c|c|c|c|c|c|}
\hline Element & Section & Steel & $\begin{array}{c}\text { Perm. load } \\
\mathrm{g} \\
\mathrm{kN} / \mathrm{m}\end{array}$ & $\begin{array}{c}\text { Var. load } \\
\mathrm{q} \\
\mathrm{kN} / \mathrm{m}\end{array}$ & $\begin{array}{c}\text { Load at SLS } \\
1.0 \mathrm{~g}+1.0 \mathrm{q} \\
\mathrm{kN} / \mathrm{m}\end{array}$ & $\begin{array}{c}\text { Load at ULS } \\
1.35 \mathrm{~g}+1.5 \mathrm{q} \\
\mathrm{kN} / \mathrm{m}\end{array}$ \\
\hline B1 & HEA360 & S235 & 17.4 & 14.5 & 31.9 & 45.3 \\
\hline B2 & IPE400 & S235 & 4.30 & 9.90 & 14.2 & 20.7 \\
\hline C1 & HEA240 & S355 & & - & - & - \\
\hline C2 & HEA240 & S235 & & - & - & - \\
\hline
\end{tabular}

Table 1 - Description of the constitutive elements and applied loads

\subsection{The joints}

All joints look like the joints of Figure 1. The end-plate thickness is always $10 \mathrm{~mm}$, and 4 bolts of quality 8.8 are used. The joint "EP2" (see Figure 2) has been submitted to test [8]. The others, showing different beam or column profiles, different steel qualities, were not submitted to test. In order to adopt a consistent approach for the modelling of the structure, the moment-rotation curve characterising the joint EP2 has been first recalculated with the rules of Eurocode 3 Annex J. A comparison has then been made with the test results. The comparison being fully satisfactory, all the other joints have then been calculated by means of 
Eurocode 3 Annex $\mathrm{J}$ on the basis of their nominal geometrical and mechanical properties, and the moment-rotation curves obtained from these calculations have been used in the here after presented simulations.

It is impossible to report here on all the results from the joint calculations. It is however interesting to show the results of the comparison between the EP2 laboratory test and the corresponding calculation. The calculations have been performed with the CoP computer program [5]. The loading, in the test as well as in the calculations, was symmetrical: it consisted in two transverse loads acting at the end of a left and a right beam stubs, applied at a distance of $1730 \mathrm{~mm}$ from the axis of the column. Figure 3 shows the experimental momentrotation curve, with many unloading and reloading phases, and the "curves" obtained by calculation.

The "EC3 curve" (trilinear type) is the strict result from calculations in accordance with Eurocode 3 [1]. It can be seen that the initial stiffness and the "plastic" resistance are in perfect agreement with the test results. The failure mode obtained from the calculation, a large deformation of the end-plate, is also confirmed by the test, as is shown in [8].

Eurocode 3 approach however disregards the effect of the steel strain-hardening. This is why a plastic plateau indicates the theoretical failure of the joint. By the way, annex $\mathrm{J}$ of EC3 does not give any information on the exact length of this plateau, but the failure mode (end-plate bending) justifies its important length anyhow.

Research undertaken by Jaspart [4] allows to take into account the effect of strainhardening in the calculation: the "modified EC3 curve" in Figure 3 shows the result of this calculation. Further resistance of the joint may be explained by membrane effect in the endplate as it deforms very largely. These two strengthening effects are however not taken into account in the simulations that are presented here below, where strict EC3 model is considered.

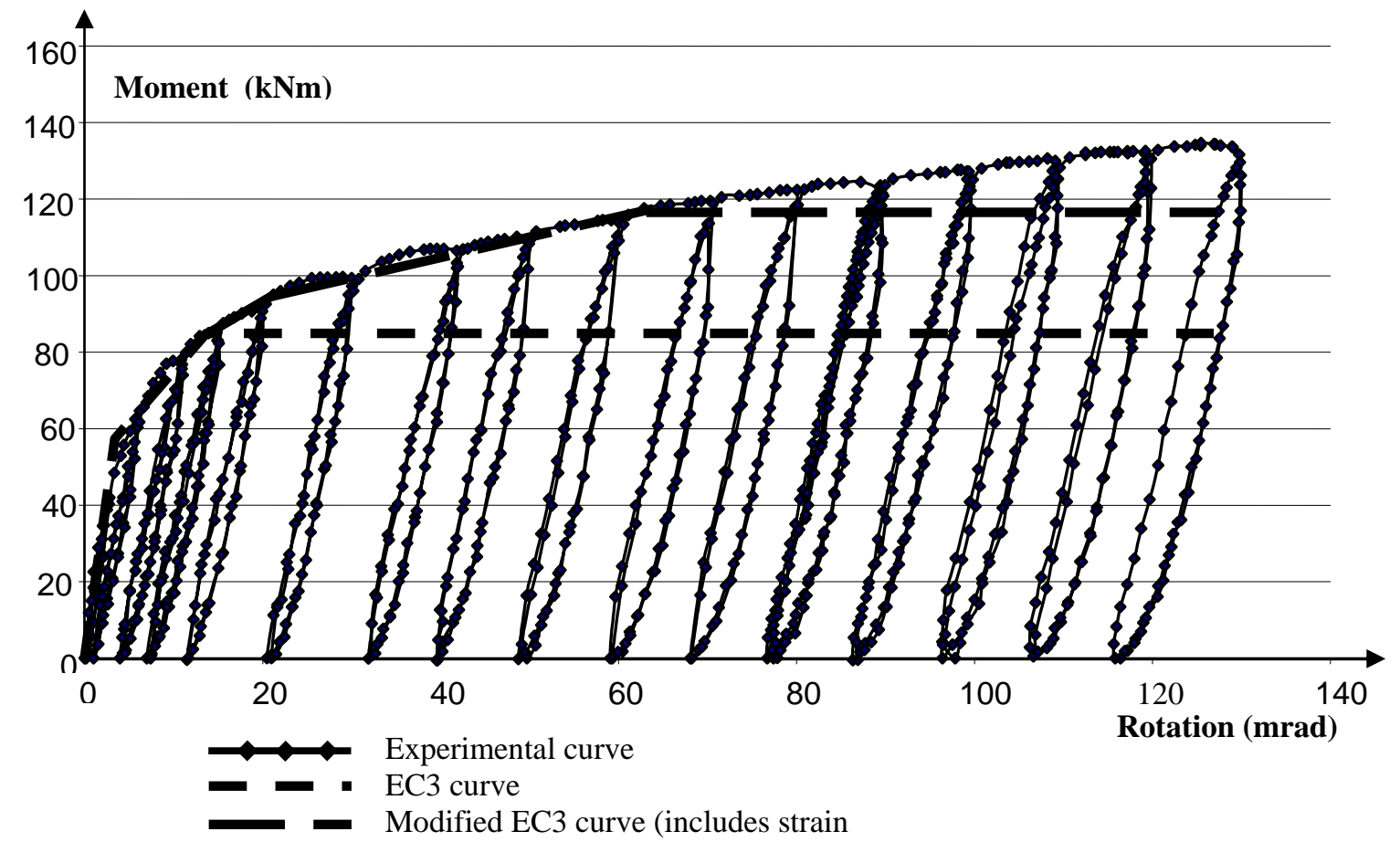

Figure 3 - Moment-rotation curves of EP2 joint 


\subsection{The residual stresses and initial imperfections}

Residual stresses have been chosen in accordance with the European Recommendations [6]. They concern all the elements of the structure. The behaviour of the steels is idealised according to the "elastic-plastic" model. Young modulus is $210.000 \mathrm{~N} / \mathrm{mm}^{2}$.

In view of the non linear analysis of the structure an initial deformation has been defined, consisting in a deformation of the three columns (Figure 4). The deformation has been obtained through a combination of the three first critical modes of elastic instability. The amplitude at the most deformed position is taken equal to $1 / 1000$ of the storey height, i.e. $3.6 \mathrm{~mm}$. The choice of the direction of the deformation for the side columns is dictated by the fact that in the calculation with semi-rigid joints, the bottom columns will be bent to the outside by the bending moments existing in the lower joints. The direction for the middle column is irrelevant.

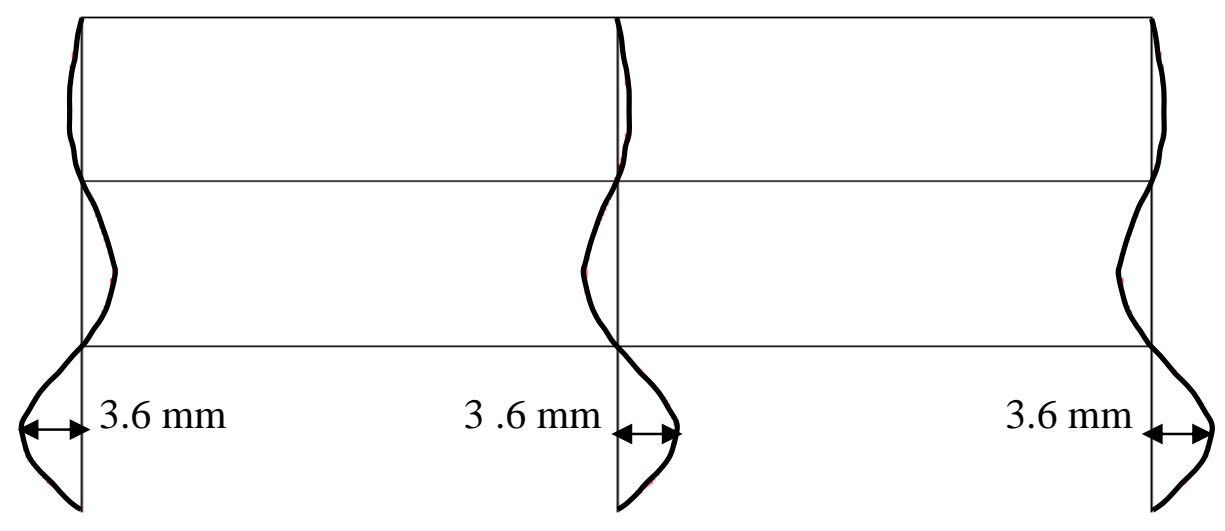

Figure 4 - Geometrical initial deformation of the structure

\section{INFLUENCE OF THE ACTUAL JOINT SEMI-RIGID RESPONSE}

In fact two cases are considered. They both refer to the structure given above, but the first case strictly comprises the loading as defined in Table 1, though the second case considers, in addition, quite important vertical additional loads at the top of the columns. The reasons are explained later.

For each case the calculation is performed once with fully pinned beam-to-column joints, and then with semi-rigid joints with a $\mathrm{M}-\phi$ response as defined by their $\mathrm{CoP}$ calculation. The calculations of the frames are performed with the full non-linear FINELG computer program [7]. The second order non-linear analyses are performed step by step up to the collapse of the structure (maximum load obtained during the loading). Instability and plasticity phenomena are taken into account. However, the analysis is here limited to the inplane behaviour of the frame because the "pinned" or "semi-rigid" character of the joints is mainly influencing this behaviour.

\subsection{First case: loading as defined in Table 1}

In the frame with assumed perfectly pinned joints ("simple" frame), the collapse is obtained by a mechanism with one plastic hinge in the middle of the all four floor beams, as shown in Figure 5.a. The maximum load factor, as compared to the load given in the last column in Table 1 (i.e. ULS), is 1.12. 
In the frame with the semi-rigid joints ("semi-rigid" frame), one obtains a mechanism in the two right floor beams (the right column is a bit weaker than the left one; see Table 1), but here with three "plastic" hinges: one in the middle of the beams and one in the two end joints. The yielding scheme is shown in Figure 5b. The load factor at collapse is here 1.28 .

In fact these load factors could have been easily obtained by hand calculation for these specific failure modes (beam plastic mechanisms). For example, knowing that the joints at the ends of the right beams have a resistance of 80.9 (centre) and $72.0 \mathrm{kNm}$ (right side), one can write, for the frame with semi-rigid joints:

$$
\frac{p_{u} L^{2}}{8} \cong \frac{80.9+72.0}{2}+M_{p l, H E A 360}
$$

$L$ being the beam length, i.e. $8830 \mathrm{~mm}$, and $M_{\text {pl,HEA360 }}$ being the plastic bending resistance of the profile section, $490 \mathrm{kNm}$. The sign $\cong$ indicates that the plastic moment in the beam does not appear exactly in the middle of the beam length. This leads to the ultimate load on the beam $p_{u}=58.12 \mathrm{kN} / \mathrm{m}$, thus a load factor $58.12 / 45.3=1.28$, what confirms the value obtained through the simulation.

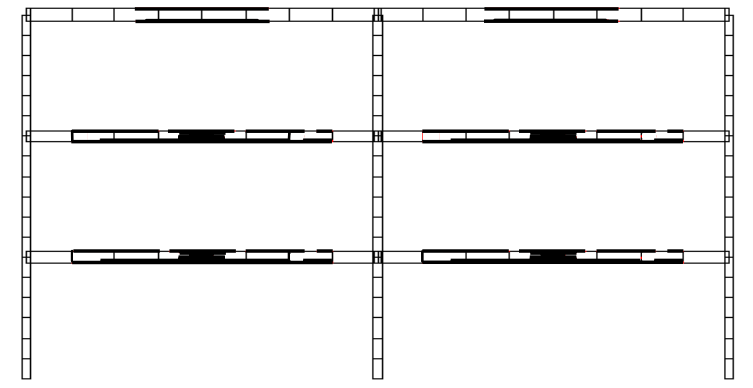

a - "Simple” frame"

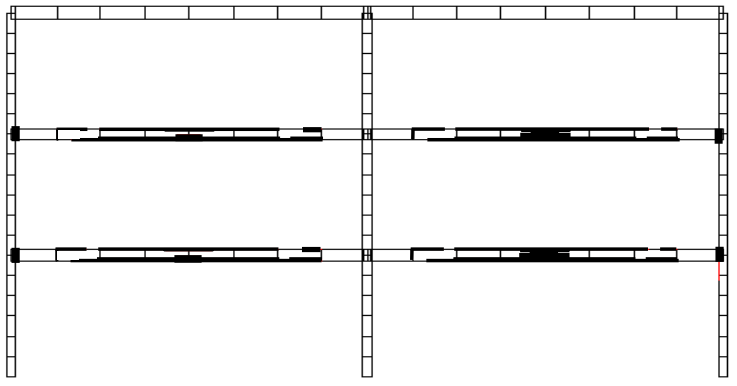

b - "Semi-rigid” frame

Figure 5 - Yielding schemes at collapse (case 1)

The load-deflection curves of the floor beams (right floor for the "semi-rigid" case) are shown for the two analyses in Figure 6.

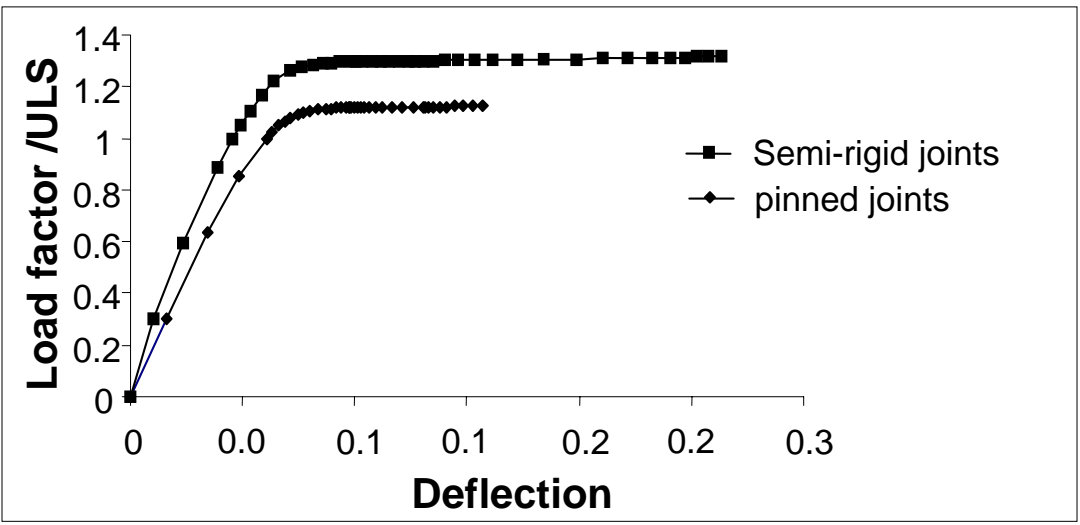

Figure 6 - Load-deflection curves for the beams on the right side 
It should be noted that the diagram in Figure 6 refers to the ULS combination as defined in Table 1. It is however clear that similar conclusions would be drawn from a diagram related to the SLS: the deflection of the beams is smaller in the "semi-rigid" assumption.

Considering a beam with two identical semi-rigid end joints, a simple calculation leads to the following ratio of the deflections "pinned", $f_{2}$, divided by "semi-rigid", $f_{1}$ :

$$
\frac{f_{2}}{f_{1}}=1-\frac{4}{5} \frac{k}{k+2}
$$

with

$$
k=S_{j . i n i} \frac{l}{E I}
$$

$S_{j . i n i}$ being the elastic initial stiffness of the joint, and $L$ the length of the beam. This is of course only valid in the elastic range of the behaviour of the structure. Taking $S_{j . i n i}=17000$ $\mathrm{kNm} / \mathrm{rad}$ as is the case in Figure 3 leads to $k=2.6$, thus $\mathrm{f}_{2} / \mathrm{f}_{1}=0.548$.

This number, 0.548 , must however be increased by the fact that the joint on the right column is more flexible than the one in the centre, and by the fact that the right column also bends, these two effects increasing the deflection $f_{2}$ of the beam. Also, as soon as the semirigid joints enter into the plastic range, this ratio increases. All these considerations could be verified by a careful study of Figure 6 .

\section{Conclusions for the first case}

It is quite obvious that the assumption "pinned joints" is conservative. Indeed:

- at any load level the displacements of the structure (the deflection of the beams) are smaller than those obtained with "semi-rigid" joints;

- the elasto-plastic collapse load, i.e. the actual resistance, is smaller.

There are however conditions for such a conclusion:

- the joints must show enough ductility, i.e. they must show a rather long plastic "plateau" as for example in Figure 3. In the above example, the rotation of the joints of the lower beams, when assumed pinned, is 19 mrad at ULS. It can be seen from the Figure 3 that the ductility of the joint is more than sufficient;

- the welds must be well designed, possibly oversized in order to avoid premature fracture and allow the joint to rotate as required (because in reality, the joints transfer bending moments);

- the design of the joint must be such that the rotation is practically possible. There are indeed cases where the rotation could be prevented after a certain amount of rotation (see for example joints FP5 and FP6 in [8]).

It must however be emphasised that the assumption "pinned joint" is not economic because the second assumption could possibly lead to a reduction of the beam profiles. This however requires further analyses and is not done here.

\subsection{Second case: modified loading}

The first case might let the reader a bit unsatisfied as the collapse mode does not concern the columns of the structure. In order to provoke a mode of collapse that would include instability of the columns, several possibilities are offered: 
- $\quad$ an increase of the resistance of the beams, for example by choosing a higher steel grade;

- a reduction of the column sections;

- $\quad$ an increase of the axial load in the columns, coming from upper storeys for example.

Increasing the resistance of the beams only will probably not reach the goal, though reduction of the column sections will probably be such that joints with the beams are no longer possible, due to insufficient space for bolt location. On the other hand it must be recognised that such frames very seldom collapse due to instability of the columns.

The problem will be solved here by increasing the steel quality of the beams from S235 to S355, and adding to the initial loading (see first case and Table 1) an axial load of $400 \mathrm{kN}$ in the columns, at each floor and roof level. This is a total of $1200 \mathrm{kN}$ for each column. The second assumption must however be regarded as unrealistic, thus somewhat academic.

The modelling of the structure, the initial deformation, residual stresses and the behaviour of the materials and the joints remain here unchanged.

$\underline{\text { Results of the simulations }}$

Collapse is now obtained, in the frame with pinned joints first, from instability in the lower part of the right column of the structure, as is shown in Figure 7. The fact that this is the right column is due to the lower steel grade of the column.

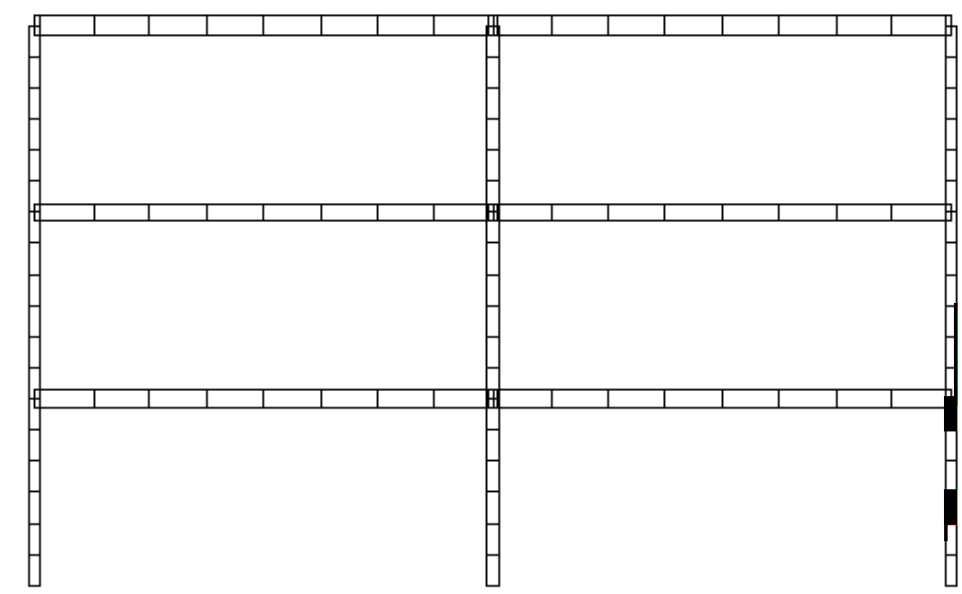

Figure 7 - Yielding scheme at collapse for the "simple" frame (case 2)

Figures 8a and 8b show the transverse deflection of the critical column (8.a), and the vertical deflection of the right floor beams (8.b).

The load factor at collapse, as compared to the ULS, is now 1.03.

The curves in Figure 8 clearly show the effects of the instability. In Figure 8.a it can be seen that the equilibrium of the column, after being passed by a maximum load-value, can only be realised for a lower load level. The deformation then increases significantly after the maximum load value. Figure 8.b is also interesting: after a linear behaviour, the load reaches its maximum value. As the load decreases, the deflection of the beam, that was still elastic, should back down on the same line. However, as the column collapses, its top part also goes down, and so the beam still deflects more, for a given load, than during the loading. At the end of the calculation the column really tumbles down and the beam irremediably follows the movement down. 

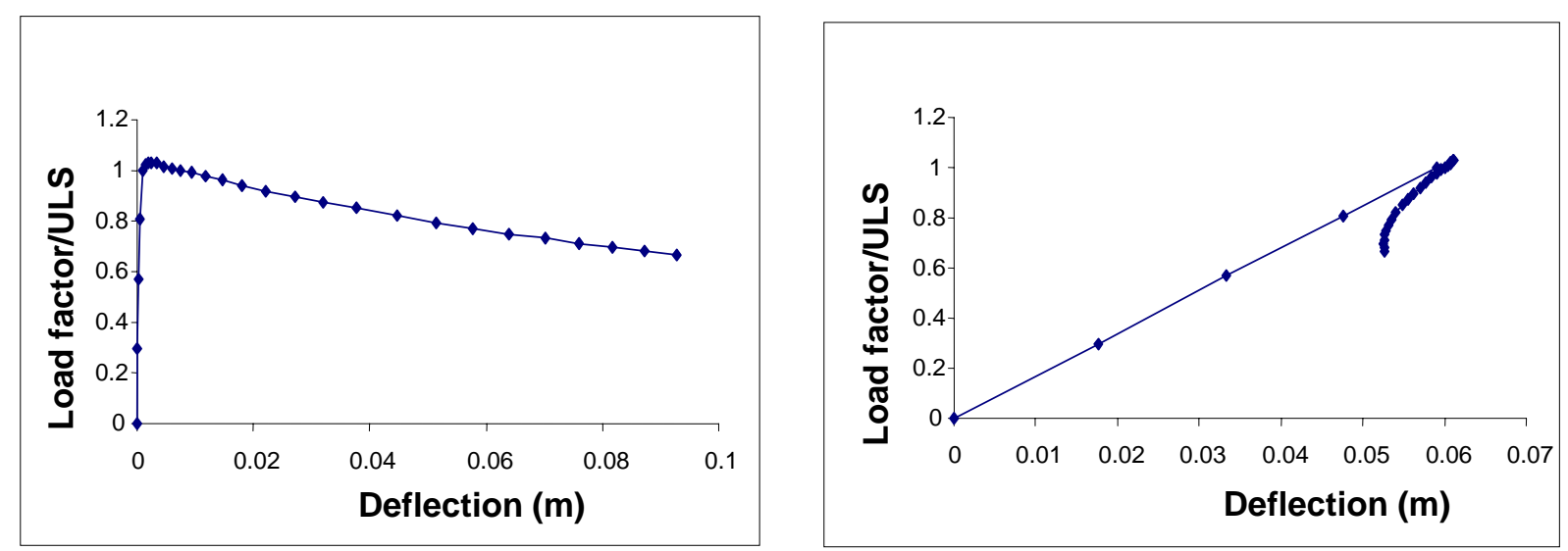

a -Transverse deflection of the buckled column b- Vertical deflection of the right lower beam

Figure 8 - Load-deflection curves for the "simple" frame

The behaviour of the frame with the semi-rigid joints is almost the same. Buckling of the bottom part of the right column also appears. Yielding scheme and load-deflection curves are similar to these corresponding to the structure with pinned joints, and thus are not reproduced here. The maximum load factor, as compared to ULS, is however here 1.00, i.e. smaller than in the case with pinned joints.

Regarding vertical deflections of the beams, similar conclusions can be drawn here as in the first load case.

\section{$\underline{\text { Conclusions for the second case }}$}

The conclusion that can be drawn from the second load case appears to be contrary to the one in the first case. Indeed the "actual" structure, with semi-rigid joints, collapses now for a load-level which lies below the maximum load level obtained in the structure in which the joints are supposed to be pinned.

This is however not surprising. It has been shown already by Gibbons et all. [3] and Gaboriau [4] that this can happen, but only in cases where the columns present very high slenderness, what is usually not the case in the type of structures which are here considered. In the above example, a similar effect has been obtained by increasing the axial loads in the columns instead of reducing their sections.

Also it must be considered, what was also shown in [3] and [4], that the lack of safety that will be obtained through the model with hinges, in these unrealistic cases, will never be higher than 3 or $4 \%$. The above example thus confirms very precisely the theoretical studies.

More physically now, the fact that the load factor is higher in the semi-rigid situation is the clear demonstration that the detrimental effect of the bending moments that are transferred to the columns, because of the stiffness of the joints, is more than compensated by the positive effect of the reduced buckling lengths of the columns due to the rotational restrains that are offered by the joints (reduction of the column buckling length).

\section{GENERAL CONCLUSIONS}

The report shows, by means of a numerical analysis of a structure, that joints that are known to present small bending resistance may be considered as hinges in a structural 
analysis, whatever is their rotational stiffness. The result is safe not only regarding the resistance or stability of the structure (in fact the risk is that the structure will be overdesigned by neglecting the positive influence of the joints), but also in terms of frame displacements, and subsequently of elastic critical resistance.

Only in case of very slender column will that assumption possibly be unsafe, but to a very small extend, never higher than 3 or $4 \%$.

This fortunately demonstrates that the assumption that has been done during decades by design engineers did not lead to unsafe constructions.

There is however a few conditions that must be fulfilled for to profess such a principle. These are:

- the joints must show enough ductility. In other words, they must fail through a ductile mode, like end plate in bending for example;

- bolts and welds must be well designed, even over-designed, in order to avoid brittle failure;

- the details of the joints must be well studied in order to allow the internal rotation to really occur.

\section{REFERENCES}

[1] Revised Annex J of Eurocode 3, Joints in Building Frames; European Prestandard ENV 1993-1-1 :1992/A2, CEN, Bruxelles, Belgium, 1998.

[2] C. GIBBONS, D. NETHERCOT, P. KIRBY and Y. WANG; An appraisal of partially restrained column behaviour in non-sway steel frames, Proc. Instn. Civ. Engrs Structs \& Bldgs, 1993, 99, pp.15-28.

[3] M. GABORIAU; Recherche d'une méthode simple de prédimensionnement des ossatures contreventées à assemblages semi-rigides dans l'optique d'une approche élastique de dimensionnement. End of study work, performed by a student from the C/U/S/T, Clermont-Ferrand (F). University of Liège (B), MSM Department, July 1995.

[4] J.P. JASPART; Etude de la semi-rigidité des assemblages et de son influence sur la résistance et la stabilité des ossatures. PHD Thesis, University of Liège (B), MSM department, 1991.

[5] CoP, The Joint Program; computer program for the calculation of joints, developed by J.P. Jaspart, University of Liège, MSM department, and K. Weynand, RWTH Aachen (D). Version 2000R19, 2000. Commercialised by ICCS bv (NL).

[6] ECCS; Ultimate Limit State calculation of frames with rigid joints. ECCS publication, Nr. 33, 1984.

[7] FINELG; Finite Elements Computer Program for non linear Analysis. MSM Department of the University of Liège (B) with financial participation of the European Community, Greisch s.a. Engineering Office (B), and ARBED (L).

[8] J.M. ARIBERT, M. BRAHAM, A. LACHAL and C. RICHARD; Testing of "simple" joints and their characterisation for structural analysis. Proceedings of the Third European Conference Eurosteel on Steel Structures, Coimbra, 19-20 September 2002, Portugal, pp. 1079-1090. 